\title{
Evaluation of the Effect of Bacillus Subtilis and Pediococcus Acidilactici Mix on Serum Biochemistry, Growth Promotation of Body and Visceral Organs in Lohmann Brown Chicks
}

http://dx.doi.org/10.1590/1806-9061-2020-1274

\section{-Author(s)}

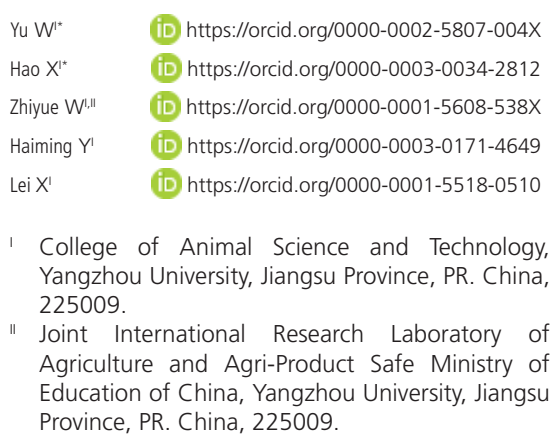

*These authors contributed equally to the paper

\section{Mail Address}

Corresponding author e-mail address Dr. Haiming Yang

College of Animal Science and Technology, Yangzhou University; address: East Wen hui Road 48, Yangzhou City, China.

Phone: +8651487979045

Email: yhmdlp@qq.com

\section{aKeywords}

Probiotic, Bacillus subtilis, Pediococcus acidilactici, chick, growth performance, serum biochemical variables.

\section{ABSTRACT}

Recently the use of antibiotic growth promoter (AGPS) in poultry feed is banned in China, leading to the increasing demand for AGPS substitutes. Probiotics have been considered as a potential substitute. The purpose of this study was to evaluate the effects of probiotic on serum biochemistry, and growth promotion of body weight and visceral organs and in Lohmann Brown chicks aged 0 to 9 weeks.

Five hundred and forty 1-day-old male chicks were randomly divided into three groups, with six replicates and 30 chicks in each replicate. The experiment was carried out over 70 days. Dietary treatments were: (1) basal diet alone (control group); (2) basal diet containing $0.1 \%$ probiotics (probiotic group); and (3) basal diet containing $0.01 \%$ zinc bacitracin in the feed (antibiotic group).

The body weight (BW) of probiotic group was significantly higher than that of the control group during the whole trial period $(p<0.05)$. ADG $(0 \sim 70 \mathrm{~d})$ in the probiotic group and the antibiotic group was higher than that in the control group $(p<0.05)$. The Oliver weight and serum total protein (TP) in the probiotic group was higher than that in the control group on the 63rd day $(p<0.05)$. The length of the duodenum, the weight of the spleen, duodenum and Jejunum in both the probiotic and antibiotic groups were higher than those in the control group $(p<0.05)$. The ileum weight in the probiotic group was significantly higher than those in the control group $(p<0.05)$. The ileum length in the probiotic group was significantly longer than that in both the antibiotic and control groups $(p<0.05)$.

Probiotic mix with Bacillus subtilis and Pediococcus acidilactici play a similar role in promoting growth of body and visceral organs, and it is a promising growth promoter for Lohmann Brown chicks (0 to 9 weeks).

\section{INTRODUCTION}

The application of antibiotics has made a great contribution to the development of animal husbandry because of its remarkable improvement in animal production performance and animal health. However, the disadvantages hidden behind the huge economic benefits brought by feed antibiotic additives have been gradually recognized. In order to eliminate the threat of antibiotic abuse to human health and at the same time to ensure the efficiency and efficiency of animal husbandry production, it is necessary to find a nontoxic, non-residual antibiotic alternative in feed additive. Under this background, feed additives that can promote growth are constantly being developed, among which probiotics are considered to be one of the best substitutes for antibiotics (Markovic, et al., 2009; Yang, et al., 2009). Probiotics are defined in the literature as "living microbial products that contribute to intestinal micro ecological balance and 


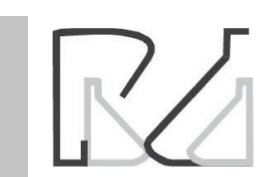

have beneficial effects on hosts by improving the properties of human or animal inherent flora" (Fuller, 1989; Isolauri et al., 1998).

Many previous studies have explored the application of Bacillus subtilis, acid-producing Streptococcus and Bacillus natto in poultry production. For example, it can improve poultry performance (Yang et al., 2012; Ribeiro et al., 2014), product quality (Mikulski et al., 2012; Zhang et al., 2012; Lei et al., 2013; Zhou et al., 2015; Youssef et al., 2013), nutrient digestibility (Li et al., 2014; Hossain, et al., 2015), and immune function (Liao et al., 2015). In addition, it can improve the environment or reduce environmental pollution (Zhang \& Kim, 2013; 2014). However, most of the studies on the beneficial effects of probiotics on birds focused on broilers (Mookiah et al., 2014; Mountzouris et al., 2010) and most of the studies in laying hens were at the age of 20 to 50 weeks (Abdelqader et al., 2013; Youssef et al., 2013; Nahashon et al., 1992; Mohebbifar et al., 2013; Panda et al., 2008). This is proof of the need to study the growth promotion effects of probiotics as an alternative of antibiotics in the early growing stage of chickens (0 to 9 weeks).

In this study, we hypothesized that under normal (not challenged with pathogens) feeding conditions, the combination of the Bacillus subtilis and Pediococcus acidilactici can replace the antibiotic to achieve the growth promoting effect of both body weight and visceral organs in the early growing stage of the layertype chicks. The purpose of this study was to evaluate the effects of probiotic (Bacillus subtilis and Pediococcus acidilactici mix) on serum biochemistry, and growth promotation of body weight and visceral organs and in Lohmann Brown chicks aged 0 to 9 weeks.

\section{MATERIAL AND METHODS}

\section{Probiotics and antibiotic}

The commercial probiotics used in this experiment (Baolai-Leelai Bioengineering Co. Ltd., Shandong, China) contain $1 \times 10^{8} \mathrm{cfu}$ Bacillus subtilis and $1 \times 10^{8} \mathrm{cfu}$ Pediococcus acidilactici per gram of product. Bacitracin zinc premix (10\% of bacitracin zinc in premix) was a representative of the antibiotic in the present study (Xinxing Veterinary Pharmaceutical Factory, Tianjin, China). There was no probiotic or antibiotic in the vitamin-mineral premix.

\section{Birds and Experimental Treatment}

All the procedures used in the experiment were approved by the Committee of Animal Protection
Evaluation of the Effect of Bacillus Subtilis and Pediococcus Acidilactici Mix on Serum Biochemistry, Growth Promotation of Body and Visceral Organs in Lohmann Brown Chicks

and Utilization institutions of Yangzhou University (Yangzhou, China). Five hundred and forty 1-day-old male Lohmann Brown chicks were purchased from a commercial hatchery (Xing Da Company, Jinhu, China) and initial BWs were obtained. The birds were randomly divided into three groups with six replicates and 30 birds in each replicate; the experimental period was 70 days. The treatments were as follows: basal diet (control group), basal diet containing $0.1 \%$ probiotics mix (probiotic group) and basal diet containing 0.01\% zinc bacitracin in feed (antibiotic group). The birds were fed the starter diets from d 1 to 42 (Starter phase) and finisher diets from d 43 to 70 (Grower phase). The nutrient levels of the diets were based on Chinese nutrient requirements for layer chickens (ZB B4300586) as shown in Table 1.

Table 1 - Ingredients and nutrient composition of diets

\begin{tabular}{|c|c|c|}
\hline Ingredient & $\begin{array}{c}\text { Starter } \\
\text { (Days } 1 \text { to } 42 \text { ) }\end{array}$ & $\begin{array}{c}\text { Grower } \\
\text { (Days } 43 \text { to } 70 \text { ) }\end{array}$ \\
\hline Corn $(\%)$ & 64.27 & 66.47 \\
\hline Soybean meal (\%) & 27.63 & 25.32 \\
\hline Corn protein powder ${ }^{2}(\%)$ & 3.00 & 0.00 \\
\hline $\operatorname{Bran}^{3}(\%)$ & 1.60 & 5.00 \\
\hline Dicalcium phosphate (\%) & 1.50 & 0.99 \\
\hline Limestone (\%) & 0.70 & 0.87 \\
\hline DL -Methionine (\%) & 0.00 & 0.05 \\
\hline $\mathrm{NaCl}(\%)$ & 0.30 & 0.30 \\
\hline Vitamin -mineral premix & 1.00 & 1.00 \\
\hline \multicolumn{3}{|l|}{ Calculated nutrition } \\
\hline composition 4,5 & 11.97 & 11.72 \\
\hline $\mathrm{ME},(\mathrm{MJ} / \mathrm{kg})$ & 19.00 & 16.25 \\
\hline$C P(\%)$ & 0.93 & 0.80 \\
\hline Lysine (\%) & 0.31 & 0.29 \\
\hline Methionine (\%) & 0.80 & 0.70 \\
\hline $\mathrm{Ca}(\%)$ & 0.71 & 0.62 \\
\hline Total P (\%) & 0.46 & 0.35 \\
\hline \multicolumn{3}{|l|}{ Available P (\%) } \\
\hline \multicolumn{3}{|c|}{$\begin{array}{l}\text { 'Nutrient level of the diets was based on Chinese nutrient requirements for layer } \\
\text { chickens (ZB B43005 -86). }\end{array}$} \\
\hline \multicolumn{3}{|c|}{$\begin{array}{l}{ }^{2} \text { Crude protein (CP) content was } 51.3 \% \text {, and metabolizable energy (ME) was } 3.41 \\
\text { Mcal/kg. }\end{array}$} \\
\hline \multicolumn{3}{|c|}{${ }^{3}$ Crude protein content was $14.3 \%$, and ME was $1.35 \mathrm{Mcal} / \mathrm{kg}$. } \\
\hline \multicolumn{3}{|c|}{ 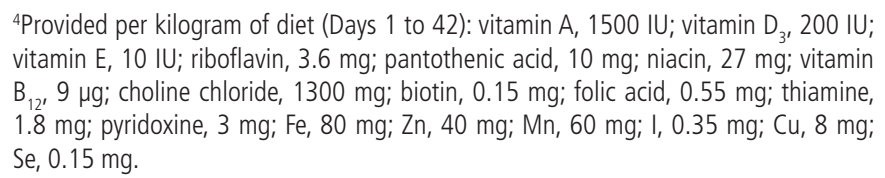 } \\
\hline \multicolumn{3}{|c|}{ 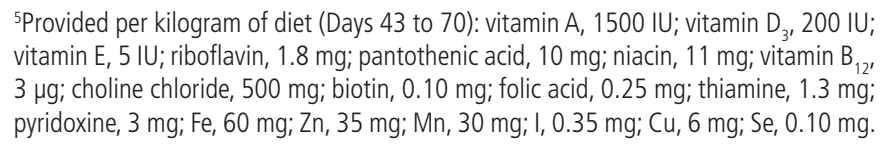 } \\
\hline \multicolumn{3}{|c|}{-control group: basal diet without probiotics and antibiotic } \\
\hline \multicolumn{3}{|c|}{-probiotic group: basal diet containing $0.1 \%$ probiotics } \\
\hline & & \\
\hline
\end{tabular}

All birds were raised in stainless steel pens of identical size. The light schedules were based on 


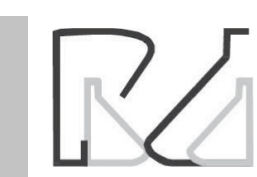

the Lohmann Commercial Management Guide. A standard Lohmann management procedure was used throughout the experiment. All birds drank and ate freely, during the experiment.

\section{Sampling and Analytical Methods}

Birds were weighed by electronic scales on days 1 , $14,28,42,56$, and 70 to determine BW and ADG. Because feed wastage could not be controlled for consumption and feed-to-gain ratio, they were not measured in the experiment.

On days 21, 42, and 63, twelve birds per treatment were randomly selected, individually weighed, and sampled for blood from the wing vein. On day 63, the birds were euthanized by cervical dislocation, and the heart, liver, spleen, bursa, and thymus were removed and weighed. The length of intestinal segments was measured when it was taken out and then it was weighed after the chyme was removed.

Before harvesting the serum, blood samples were centrifuged at $1800 \times g$ for $10 \mathrm{~min}$ at $4^{\circ} \mathrm{C}$ after clotting. Serum samples were stored at $-20^{\circ} \mathrm{C}$ until their variables were measured.

The serum growth hormone $(\mathrm{GH})$ was determined using lodine [125I] Growth Hormone Radioimmunoassay kits (North Biological Technology Research Institute, Beijing, China) according to the manufacturer's instructions.

Serum biochemical variables, total protein (TP), albumin (ALB), glucose (GLU), and alkaline phosphatase (ALP), were measured using the Unicel
Evaluation of the Effect of Bacillus Subtilis and Pediococcus Acidilactici Mix on Serum Biochemistry, Growth Promotation of Body and Visceral Organs in Lohmann Brown Chicks

Dxc 800 Synchron Automatic biochemistry analyzer system (Beckman Coulter, Brea, CA, USA).

\section{Statistical Analysis}

Data were input into an Excel spreadsheet to establish a database and analyzed using a one-way ANOVA (SPSS 17.0, SPSS Inc. and Chicago, IL, USA) to determine differences between treatment groups. Differences were significant when $p<0.05$.

\section{RESULTS}

\section{Growth Performance}

The results of growth performance of birds are presented in Table 2. Birds in the probiotic group had greater BW than in the control group during the overall experimental period $(p<0.05)$. On the 14th day, the weight of poultry in probiotic group was higher than that in antibiotic group $(p<0.05)$, but there was no significant difference between probiotic group and antibiotic group on the 28th and 70th day ( $p>0.05)$. On the 56th and 70th day, compared with the control group, the addition of antibiotic led to the improvement of BW $(p<0.05)$. The probiotic group had higher ADG from day 1 to 14 and day 56 to 70 compared with the control group $(p<0.05)$. The antibiotic group had higher ADG from days 42 to 56 compared with the control group $(p<0.05)$. Probiotic treatment or antibiotic treatment led to increased ADG during the overall experimental period compared with the control group $(p<0.05)$. On the 14 th day of the experiment, BW and ADG in probiotic group were higher than those in antibiotic group $(p<0.05)$.

Table 2 - Effects of probiotics/antibiotics on growth performance in Lohmann Brown chicks.

\begin{tabular}{|c|c|c|c|c|}
\hline Parameter & Age (d) & Control group1 & Probiotic group & Antibiotic group \\
\hline BW (g) & 1 & $36.6 \pm 2.3$ & $36.2 \pm 2.0$ & $36.0 \pm 2.1$ \\
\hline \multirow[t]{6}{*}{ BW (g) } & 1 & $36.6 \pm 2.3$ & $36.2 \pm 2.0$ & $36.0 \pm 2.1$ \\
\hline & 14 & $142 \pm 2^{a}$ & $146 \pm 1.0^{b}$ & $142 \pm 2.0^{a}$ \\
\hline & 28 & $308 \pm 14^{a}$ & $320 \pm 10^{b}$ & $315 \pm 8.0^{\mathrm{ab}}$ \\
\hline & 42 & $560 \pm 20^{a}$ & $578 \pm 21^{b}$ & $573 \pm 15^{\mathrm{ab}}$ \\
\hline & 56 & $715 \pm 20^{a}$ & $765 \pm 34^{b}$ & $757 \pm 37^{b}$ \\
\hline & 70 & $943 \pm 68^{a}$ & $1016 \pm 36^{b}$ & $1005 \pm 48^{b}$ \\
\hline \multirow[t]{6}{*}{ ADG (g) } & 1 to 14 & $7.52 \pm 0.26^{a}$ & $7.87 \pm 0.14^{b}$ & $7.58 \pm 0.16^{a}$ \\
\hline & 14 to 28 & $11.9 \pm 0.90$ & $12.4 \pm 0.70$ & $12.3 \pm 0.60$ \\
\hline & 28 to 42 & $18.0 \pm 0.50$ & $18.4 \pm 1.00$ & $18.5 \pm 0.60$ \\
\hline & 42 to 56 & $11.1 \pm 0.90^{\mathrm{a}}$ & $13.4 \pm 1.10^{b}$ & $13.1 \pm 2.4^{b}$ \\
\hline & 56 to 70 & $16.2 \pm 3.8$ & $17.9 \pm 1.16$ & $17.7 \pm 1.7$ \\
\hline & 1 to 70 & $12.9 \pm 1.0^{a}$ & 14.0 & \\
\hline
\end{tabular}

Note: ${ }^{a-b}$ Different superscript letters within a row indicate a statistically significant difference $(p<0.05)$.

-control group: basal diet without probiotics and antibiotic

-probiotic group: basal diet containing $0.1 \%$ probiotics

-antibiotic group: basal diet containing $0.01 \%$ zinc bacitracin mix $(10 \%)$. 


\section{Serum Biochemical Variables}

The results of serum biochemical variables of birds are show in Table 3. Serum ALB of the probiotic group was higher than the control group and the antibiotic group on day $21(p<0.05)$. Furthermore, the inclusion of probiotics resulted in increased TP compared with the control group and antibiotic group on day 63 $(p<0.05)$. There was no significant difference between the treatments group birds with respect to ALP, GLU, and $\mathrm{GH}(p>0.05)$.

Table 3 - Effects of probiotics /antibiotics on serum biochemical variables in Lohmann Brown chicks.

\begin{tabular}{|c|c|c|c|c|}
\hline Parameter & Age (d) & Control group & Probiotic group & Antibiotic group \\
\hline ALB & 21 & $11.1 \pm 0.40^{a}$ & $11.8 \pm 0.70^{b}$ & $11.4 \pm 0.90^{\mathrm{ab}}$ \\
\hline \multirow[t]{2}{*}{$(g / L)$} & 42 & $11.3 \pm 0.40$ & $11.6 \pm 0.80$ & $11.6 \pm 0.70$ \\
\hline & 63 & $12.0 \pm 1.0$ & $11.8 \pm 0.60$ & $11.5 \pm 0.90$ \\
\hline TP & 21 & $28.6 \pm 1.0$ & $29.9 \pm 1.6$ & $29.4 \pm 2.3$ \\
\hline \multirow[t]{2}{*}{$(g / L)$} & 42 & $32.3 \pm 1.1^{\mathrm{ab}}$ & $33.2 \pm 1.1^{\mathrm{a}}$ & $31.2 \pm 1.7^{b}$ \\
\hline & 63 & $32.3 \pm 1.2^{\mathrm{a}}$ & $33.6 \pm 1.6^{b}$ & $31.4 \pm 1.6^{a}$ \\
\hline ALP & 21 & $1940 \pm 718$ & $2044 \pm 642$ & $2087 \pm 942$ \\
\hline \multirow[t]{2}{*}{$(\mathrm{U} / \mathrm{L})$} & 42 & $1578 \pm 591$ & $1995 \pm 774$ & $2105 \pm 459$ \\
\hline & 63 & $828 \pm 186$ & $778 \pm 266$ & $766 \pm 194$ \\
\hline GLU & 21 & $15.8 \pm 1.3$ & $15.2 \pm 0.80$ & $15.4 \pm 1.2$ \\
\hline \multirow[t]{2}{*}{$(\mathrm{mmol} / \mathrm{L})$} & 42 & $14.1 \pm 0.60$ & $13.7 \pm 0.90$ & $13.8 \pm 0.90$ \\
\hline & 63 & $11.9 \pm 0.60$ & $12.5 \pm 0.70$ & $11.6 \pm 1.8$ \\
\hline $\mathrm{GH}$ & 21 & $855 \pm 131$ & $871 \pm 172$ & $891 \pm 90.0$ \\
\hline \multirow[t]{2}{*}{$(\mathrm{ng} / \mathrm{ml}) * 10^{3}$} & 42 & $892 \pm 191$ & $873 \pm 385$ & $867 \pm 92.0$ \\
\hline & 63 & $863 \pm 84.0$ & $839 \pm 63.0$ & $805 \pm 129$ \\
\hline
\end{tabular}

Note: a-bDifferent superscript letters within a row indicate a statistically significant difference $(p<0.05)$.-control group: basal diet without probiotics and antibiotic -probiotic group: basal diet containing $0.1 \%$ probiotics

-antibiotic group: basal diet containing $0.01 \%$ zinc bacitracin mix (10\%).

\section{Visceral Organs}

The results of the growth of the small intestine are show in Table 4. The duodenum was significantly longer in the probiotic and antibiotic groups compared to the control group $(p<0.05)$. The probiotic group had significantly longer ileums compared with the control and antibiotic groups $(p<0.05)$. In addition, the weight of duodenum and ileum in birds fed the probiotic feed was significantly higher than that in the control group $(p<0.05)$. The weight of the duodenum in the probiotic group and antibiotic group was significantly higher than that in the control group $(p<0.05)$. There was no significant difference between the treatment group birds with respect to the Length and weight of the Jejunum. There was significant difference between the probiotic group and antibiotic group, only in the ileum length $(p<0.05)$, but there was no significant difference in other variables.

Table 4 - Effects of probiotics/antibiotics on small intestine growth in Lohmann Brown chicks on day 63.

\begin{tabular}{|c|c|c|c|}
\hline Variables & Control group & Probiotic group & Antibiotic group \\
\hline Duodenum length $(\mathrm{cm})$ & $22.4 \pm 1.4^{a}$ & $24.6 \pm 2.4^{b}$ & $24.3 \pm 2.4^{b}$ \\
\hline Jejunum length $(\mathrm{cm})$ & $49.7 \pm 6.4$ & $47.5 \pm 5.2$ & $47.0 \pm 3.4$ \\
\hline Ileum length (cm) & $42.4 \pm 4.2^{\mathrm{a}}$ & $47.3 \pm 4.8^{b}$ & $43.8 \pm 2.8^{a}$ \\
\hline Duodenum weight (g) & $5.01 \pm 0.67^{a}$ & $5.61 \pm 0.82^{b}$ & $5.66 \pm 0.57^{b}$ \\
\hline Jejunum weight (g) & $9.41 \pm 0.87$ & $10.03 \pm 0.85$ & $9.68 \pm 1.43$ \\
\hline Ileum weight (g) & $5.43 \pm 0.95^{a}$ & $6.38 \pm 0.73^{b}$ & $6.01 \pm 0.87^{\mathrm{ab}}$ \\
\hline
\end{tabular}

Note: ${ }^{\mathrm{a}-\mathrm{b}}$ Different superscript letters within a row indicate a statistically significant difference $(\mathrm{p}<0.05)$.-control group: basal diet without probiotics and antibiotic

-probiotic group: basal diet containing $0.1 \%$ probiotics

-antibiotic group: basal diet containing $0.01 \%$ zinc bacitracin mix (10\%).

The results of visceral organ growth are show in Table 5 . The addition of probiotics resulted in significantly increased $(p<0.05)$ liver weights compared with the control. Birds fed either the probiotic or antibiotic diet had higher spleen weights than the control birds $(p<0.05)$. However, there was no significant difference in heart, thymus, and bursa weights between treatment group birds ( $p>0.05)$. 
Table 5 - Effects of probiotics/antibiotics on other visceral organs growth in Lohmann Brown chicks on day 63.

\begin{tabular}{llll}
\hline Organ weight $(\mathrm{g})$ & Control group & Probiotic group & Antibiotic group \\
\hline Heart & $3.88 \pm 0.50$ & $4.02 \pm 0.33$ & $4.05 \pm 0.25$ \\
Liver & $18.6 \pm 2.4^{\mathrm{a}}$ & $21.4 \pm 2.8^{\mathrm{b}}$ & $20.7 \pm 3.3^{\mathrm{ab}}$ \\
Spleen & $2.12 \pm 0.45^{\mathrm{a}}$ & $2.66 \pm 0.59^{\mathrm{b}}$ & $2.69 \pm 0.82^{\mathrm{b}}$ \\
Thymus & $3.45 \pm 0.92$ & $3.53 \pm 0.66$ & $3.56 \pm 0.99$ \\
Bursa & $0.34 \pm 0.07$ & $0.40 \pm 0.12$ & $0.34 \pm 0.07$ \\
\hline
\end{tabular}

Note: ${ }^{a-b}$ Different superscript letters within a row indicate a statistically significant difference $(p<0.05)$.

-control group: basal diet without probiotics and antibiotic

-probiotic group: basal diet containing $0.1 \%$ probiotics

-antibiotic group: basal diet containing $0.01 \%$ zinc bacitracin mix (10\%).

\section{DISCUSSION}

It is well known that growth and development in chickens are influenced by the different numbers and types of normal flora colonization in the intestinal mucosa and intestinal contents (Chichlowski et al., 2007; Hernández et al., 2008; Choct, 2009). Probiotics is a new feed additive as a potential substitute for antibiotic. The organic acids produced by probiotics can directly kill pathogenic bacteria or form a microenvironment that is not conducive to the growth of harmful bacteria, thus improves immune function (Zulkifli et al., 2000; Panda et al., 2008) and nutrient retention (Nahashon et al., 1994; Mountzouris et al., 2010). The organic acids such as lactic acid and acetic acid produced by probiotics can reduce the $\mathrm{pH}$ value of the intestinal tract and create the microecological environment which is beneficial to the growth and reproduction of the probiotic bacteria, increase the number of beneficial bacteria and inhibit the growth of pathogenic microorganisms (Koenen et al., 2004; An et al., 2008; Mountzouris et al., 2010). The body weight (BW) and ADG of the probiotic group were higher than those of the control group during the whole experiment period, which indicated that probiotics promoted the growth of Lornman chicken. This was in agreement with previous studies in broilers (Zulkifli et al., 2000; Timmerman et al., 2006; Wang \& Gu, 2010). On the contrary, other studies (Lee et al., 2010; Zhang et al., 2011) reported no beneficial effects on chicken growth performance. Different probiotics have favorable or unfavorable effects on the body through a variety of complex and interactive mechanisms. The difference of experimental results may be due to the different types of probiotics and the level of feeding and management. In the current experiment, the addition of a mix of Bacillus subtilis $\left(1 \times 10^{5} \mathrm{cfu} / \mathrm{kg}\right.$ of diet) and Pediococcus acidilactici ( $1 \times 10^{5} \mathrm{cfu} / \mathrm{kg}$ of diet) significantly increased the BW and ADG in Lohmann Brown chicks. Similarly Bacillus subtilis was reported to improve body weight gain in broilers (Fritts et al., 2000; Hooge et al., 2004). The reason may be that Bacillus subtilis increases the height of villi, which can provide more surface areas to absorb nutrients (Sen et al., 2012) and reduce pathogenic bacteria in the intestine, thus improving nutrient absorption (Wu et al., 2011; Park \& Kim, 2015). The addition of lactic acid bacteria can also improve the intestinal structure and promote the absorption and utilization of more nutrients (Chichlowsk et al., 2007; Awad et al., 2009). Furthermore, Pediococcus acidilactici-based probiotics can effectively enhance the resistance of birds to coccidiosis and partially protected against the negative growth effects associated with infection (Lee et al., 2007) therefore leading to an improved growth performance. In this study, the addition of the probiotic group improved the length of the duodenum and the jejunum of Lohmann Brown chicks on day 63. This is similar to the results reported by Awad et al. (2009). This indicated that the probiotics mix might have improved growth performance by increasing intestinal length and greater nutrient absorption. The results showed that the probiotics could improve the growth performance of chickens, which was similar to that of antibiotic. Probiotic supplementation did not affect the serum levels of ALP, GLU, or GH. However, in the probiotic group, ALB on day 21 and TP on day 63 were significantly higher than those in the control group. The good nutritional status can maintain the serum total protein and the albumin content at a high level, and the increase of the both contents of the two shows that the metabolic activity of the body is vigorous (Dhanalakshmi et al., 2007).

In the current study, we found that liver weights were significantly higher in the probiotic group compared with the control group. This was in agreement with the study of Wang et al. (2014), whereas, not in line with the result of Awad et al. (2009) who reported no effect on liver weights. The spleen is an important lymphoid organ, which produces immunoglobulins, 
complement, and other immune substances that play an important role in immunity. Chen et al. (2013) suggested measuring immune organ weight as a method for evaluating immune status in chickens. Spleen weight could be increased with spleen swelling under pathological conditions (Syed et al., 2012). Whereas, under the normal situation of the present study, the higher spleen weight in the probiotic group and antibiotic group suggested that the probiotic diet can improve the immune function of the body, which is consistent with the observation of Li et al. (2009). In addition, under pathological conditions, there was no interaction between coccidiosis vaccine and feed additives on growth performance and carcass yield of broilers, and probiotics could be safely used in broilers feed (Xi et al., 2019). This is also demonstrated by the data of the present study, where the body weight of the probiotic group was higher than the antibiotic group.

There was no significant difference between the probiotic group and the antibiotic group in the organs (heart, liver, spleen, thymus, and bursa) weights, which indicated that dietary supplementation with probiotics mix or antibiotic had similar influence on the growth of the heart, liver, and main immune organs of chickens.

\section{CONCLUSION}

In conclusion, adding Bacillus subtilis and Pediococcus acidilactici mix to chicken feed resulted in similar effect as zinc bacitracin, an alternative to antibiotics, where the growth of body weight and visceral organs were promoted in Lohmann Brown chicks (0 to 9 weeks). Therefore, Bacillus subtilis and Pediococcus acidilactici mix is a promising growth promoter for Lohmann Brown chicks (0 to 9 weeks) under non-pathological state.

\section{ACKNOWLEDGMENTS}

This research was financially supported by the Support Project of Science and Technology Special Funds in the northern region of Jiangsu province (Enriching the people and strengthening the county, SZ-SQ2018045) and the Earmarked Fund for Jiangsu Agricultural Industry Technology SystemJATS[2019]017.

\section{REFERENCES}

An B, Cho B, You S, Paik H, Chang H, Kim S, ET AL. Growth performance and antibody response of broiler chicks fed yeast derived $\beta$ glucan and single-strain probiotics. Asian-Australasian Journal of Animal Sciences 2008;21:1027-1032
Abdelqader A, Al-Fataftah AR, Das G. Effects of dietary Bacillus subtilis and inulin supplementation on performance, eggshell quality, intestinal morphology and microflora composition of laying hens in the late phase of production. Animal Feed Science and Technology 2013:179:103-111.

Awad W, Ghareeb K, AbdelRaheem S, Hm JB. Effects of dietary inclusion of probiotic and synbiotic on growth performance, organ weights, and intestinal histomorphology of broiler chickens. Poultry Science 2009;88:49-56

Chichlowski M, Croom WJ, Edens FW. Microarchitecture and spatial relationship betweenbacteria and ileal, cecal and colonic epithelium in chicks fed a directfed microbial, prima Lac, andsalinomycin. Journal Poultry Science 2007;86:1121-1132.

Choct M. Managing gut health through nutrition. Journal British Poultry Science 2009;50:9-15.

Chen W, Wang J, Yan L, Huang J. Evaluation of probiotics in diets with different nutrient densities on growth performance, blood characteristics, relative organ weight and breast meat characteristics in broilers. British Poultry Science 2013;54:635-641.

Dhanalakshmi S, Devi RS, Srikuma R. Protective effect of Triphala on cold stressinduced behavioral and biochemical abnormalities in rats. Yakugaku zasshi journal of the Pharmaceutical Society of Japan 2007;127(11):1863-1867.

Fritts C, Kersey J, Motl M, Kroger E, Yan F, Si J, Jiang Q, et al. Bacillus subtilis C3102 (Calsporin) improves live performance and microbiological status of broiler chickens. Journal Applied Poultry Research 2000;9:149-155.

Fuller, R. Probiotics in man and animals. Journal of Applied Bacteriology 1989;66: 365-378.

Hooge DM, Ishimaru H, Sims MD. Influence of dietary Bacillus subtilis C3102 spores on liveperformance of broiler chickens in four controlled pen Trials. Journal of Applied Poultry Research 2004;13:222-228.

Hernández IG, Delgadillo AT, Vorackova FV. Intestinal flora, probiotics, and cirrhosis. Annals of Hepatology 2008;7:120-124.

Hossain MM, Begum M, Kim IH. Effect of Bacillus subtilis, Clostridium butyricum and Lactobacillus acidophilus endospores on growth performance, nutrient digestibility, meat quality, relative organ weight, microbial shedding and excreta noxious gas emission in broilers. Veterinarni Medicina -Czech 2015;60:77-86.

Isolauri ES Salminen A, Ouwehand C. Probiotics. Best Practice \& Research: Clininal Gastroenterology 2004;118:299-313.

Koenen M, Kramer J, Hulst R. van der, Heres L, Jeurissen S, Boersma W. Immunomodulation by probiotic lactobacilli in layerand meattype chickens. British Poultry Science 2004;45:355-366.

Lee $K$, Lee S, Lillehoj h, Li G, Jang S, Babu U, et al. Effects of directfed microbials on growth performance, gut morphometry, and immune characteristics in broiler chickens. Poultry Science 2010;89:203-216.

Lee SH, Lillehoj HS, Dalloul RA, Park DW, Hong YH, Lin JJ. Influence of Pediococcusbased probiotic on coccidiosis in broiler chickens. Poultry Science 2007;86:63-66

Lei K, Li YL, Yu DY, Rajput IR, Li WF. Influence of dietary inclusion of Bacillus licheniformis on laying performance, egg quality, antioxidant enzyme activities, and intestinal barrier function of laying hens. Poultry Science 2013;92:2389-95.

Li S, Zhao X, Wang J. Synergy of Astragalus polysaccharides and probiotics (Lactobacillus and Bacillus cereus) on immunity and intestinal microbiota in chicks. Poultry Science 2009;88:519-525. 
Li YB, Xu QQ, Yang CJ, Yang X, Lv L, Yin CH, et al. Yan. Effects of probiotics on the growth performance and intestinal micro flora of broiler chickens. Pakistan Journal of Pharmaceutical Science 2014;27:713717.

Liao XD, Ma G, Cai J, Fu Y, Yan XY, Wei XB, et al. Effects of Clostridium butyricum on growth performance, antioxidation, and immune function of broilers. Poultry Science 2015;94:662-667.

Markovic R, Sefer D, Krstic M. Effect of different growth promoters on broiler performanceand gut morphology. Archivos de Medicina Veterinaria 2009;41:163-169.

Mikulski D, Jankowski J, Naczmanski J, Mikulska M, Demey V. Effects of dietary probiotic (Pediococcus acidilactici) supplementation on performance, nutrient digestibility, egg traits, egg yolk cholesterol, and fatty acid profile in laying hens. Poultry Science 2012;91:2691-2700.

Mohebbifar A, Kashani S, Afsari M, Torki M. Effects of commercial prebiotic and probiotics of diet on performance of laying hens, egg traits and some blood parameters. Annual Reserch \& Review in Biology 2013;3:921-34.

Mookiah S, Sieo CC, Kalavathy R, Abdullah N, Ho YW. Effects of dietary prebiotics, probiotic and synbiotics on performance, caecal bacterial populations and caecal fermentation concentrations of broiler chickens. Journal of the Science of Food in Agriculture 2014;94:341-348.

Mountzouris KC, Tsitrsikos P, Palamidi I, Arvaniti A, Mohnl M, Schatzmayr $G$, et al. Effects of probiotic inclusion levels in broiler nutrition on growth performance, nutrient digestibility, plasma immunoglobulins, and cecal microflora composition. Poultry Science 2010;89:58-67.

Nahashon SN, Nakaue HS, Mirosh LW. Effect of direct-fed microbials on nutrient retention and production parameters of laying pullets. Poultry Science 1992;71:111.

Nahashon SN, Nakaue HS, Mirosh LW. Production variables and nutrient retention in Single Comb White Leghorn laying pullets fed diets supplemented with direct-fed microbials. Poultry Science 1994;73:1699-1711.

Park J, Kim I. The effects of the supplementation of Bacillus subtilis RX7 and B2A strains on the performance, blood profiles, intestinal Salmonella concentration, noxious gas emission, organ weight and breast meat quality of broiler challenged with Salmonella typhimurium. Journal of Animal Physiology and Animal Nutrition 2015;99:326-334.

Panda AK, Rama Rao S, Raju MVLN, Sharma SS. Effect of probiotic (Lactobacillus sporogenes) feeding on egg production and quality, yolk cholesterol and humoral immune response of White Leghorn layer breeders. Journal of the Science of Food in Agriculture 2008;88:43-47.

Ribeiro V, Albino LFT, Rostagno HS, Barreto SLT, Hannas MI, Harrington D, et al. Effects of the dietary supplementation of Bacillus subtilis levels on performance, egg quality and excreta moisture of layers. Animal Feed Science 2014;195:142-146.

Syed Habib-ur-Rehman, Khan MS, Khan H, Ahmad N, Bhatii WM. Incidence and gross pathology of Salmonella gallinarium infection in chicken. Journal of Animal and Veterinary Advances 2004;3:175-178.

Sen S, Ingale SL, Kim YW, Kim JS, Kim KY,Lohakare JD, et al. Chae. Effect of supplementation of Bacillus subtilis LS 1-2 to broiler diets on growth performance, nutrient retention, caecal microbiology and small intestinal morphology. Research in Veterinary Science 2012;93:264268.

Timmerman $H$, Veldman A, Elsen E van den, Rombouts $F$, Beynen A. Mortality and growth performance of broilers given drinking water supplemented with chickenspecific probiotics. Poultry Science 2006;85:1383-1388
Wu BQ, Zhang T, Guo LQ. Effects of Bacillus subtilis KD1 on broiler intestinal flora. Poultry Science 2011;90:2493-2499.

Wang W, Yang H, Wang Z, Han J, Zhang D, Sun H, et al. Effects of prebiotic supplementation on growth performance, slaughter performance, growth of internal organs and small intestine and serum biochemical variables of broilers. Journal Applied Poultry Research 2014;43:33-38.

Wang Y, Gu Q. Effect of probiotic on growth performance and digestive enzyme activity of Arbor Acres broilers. Research in Veterinary Science 2010;9:163-167.

Xi W, Peebles ED, Kiess AS, Wamsley KGS, Zhai W. Effects of coccidial vaccination and dietary antimicrobial alternatives on the growth performance, internal organ development, and intestinal morphology of Eimeria-challenged male broilers. Poultry Science 2019;98:20542065.

Yang Y, Ji PA, Choct M. Dietary modulation of gut microflora in broiler chickens:a review ofthe role of six kinds of alternatives to in-feed antibiotics. World's Poultry Science Journal 2009;65:97-114.

Yang CM, Cao GT, Ferket PR, Liu TT, Zhou L, Zhang L, et al. Effects of probiotic, Clostridium butyricum, on growth performance, immune function, and cecal microflora in broiler chickens. Poultry Science 2012;91:2121-2129

Youssef AW, Hassan H, Ali H, Mohamed M. Effect of Probiotics, prebiotics and organic acids on layer performance and egg quality. Asian Journal of Poultry Science 2013;7:65-74.

Zhang B, Yang X, Guo Y, Long F. Effects of dietary lipids and Clostridium butyricum on the performance and the digestive tract of broiler chickens. Archives of Animal Nutrition 2011;65:329-339.

Zhang JL, Xie QM, Ji J, Yang WH, Wu YB, Li C, et al. Different combinations of probiotics improve the production performance, egg quality, and immune response of layer hens. Poultry Science 2012;91:2755-2760.

Zhang ZF, Cho JH, Kim IH. Effects of Bacillus subtilis UBTMO2 on growth performance, relative immune organ weight, gas concentration in excreta, and intestinal microbial shedding in broiler chickens. Livestock Science 2013;155:343-347

Zhang ZF, Kim IH. Effects of probiotic supplementation in different energy and nutrient density diets on performance, egg quality, excreta microflora, excreta noxious gas emission, and serum cholesterol concentrations in laying hens. Journal Animal Science 2013;91:47814787.

Zhang ZF, Kim IH. Effects of multistrain probiotics on growth performance, apparent ileal nutrient digestibility, blood characteristics, cecal microbial shedding, and excreta odor contents in broilers. Poultry Science 2014;93:364-370.

Zhou X, Jin E, Li S, Wang C, Qiao E, Wu G. Effects of dietary supplementation of probiotics (Bacillus subtilis, Bacillus licheniformis, and Bacillus natto) on broiler muscle development and meat quality. Turkish Journal of Veterinary and Animal Sciences 2015;39:203-210.

Zulkifli I, Abdullah N, Azrin NM, Ho Y. Growth performance and immune response of two commercial broiler strains fed diets containing Lactobacillus cultures and oxytetracycline under heat stress conditions. British Poultry Science 2000;41:593-597. 
